\title{
MANAGEMENT OF ACTIVITIES IN THE OPENING OF SPORTING EVENTS THROUGH THE TECHNIQUES OF NETWORK PLANNING
}

\author{
Sretenka Dugalić ${ }^{1}$ \\ ${ }^{1}$ College of Sport and Health, Belgrade, Serbia
}

\section{SUMMARY}

This paper presents an exemplar of how network planning technique can be applied within sport management. Sporting events involve a very large number of participants (excluding the audience, sponsors and members of the media, the Olympic Games often encounter over 10,500 participants). Because some sporting events last several days, constantly being updated, it is possible to use prior experience. However, considering that sport managers often have the task of preparing and organizing sporting events that take place in a relatively short period of time, the specifications required are primarily limited by time resources.

The aim is therefore to provide assistance to and share experiences with potential users and the organizers of sporting events by emphasizing the importance of network planning techniques to the management of sport, which itself needs to have a greater application within sport management to increase organizational resources, and possibly, contribute to the saving of other resources, particularly money, people and equipment.

The examples of network planning techniques (Critical Path Method - CPM, Program Evolution and Review Technique - PERT) shown in this paper are the result of the author's many years of experience with their practical application and implementation, and aspirations to see, as much as possible, contemporary theoretical achievements find their place within sports management. In this way, the field of management and business are themselves affirmed, creating the basis for further developments within the sporting events discipline, whilst contributing to the formation of new ideas, and improving sporting systems and institutions.

Key Words: CPM method, manegement of sporting events, network planning techniques.

\section{INTRODUCTION}

The method of planning theory utilizing critical path (critical path method - CPM) is a project management technique developed in 1950 by Morgan R. Walker, whilst working for DuPont and E. Kelley, Jr., for the Remington Rand (Kelley, 1961; Kelley \& Walker, 1959). Since then, the technique has found its application in all areas of the economy and noneconomy (Dugalic, 1995), as well as in sports and the management of sport (Appenzeller, 2000), which is understandable when it is known that the resources in this area are very limited, and the requirements for sporting-economic efficiency is exposed to growing expectations and competitive pressures as a result of rapid globalization (Raič, 2006).
This paper presents a model for organizing sporting events using network planning techniques, with the intent of facilitating, on the basis of these experiences, the work of sports organizers and coordinators. With the aid of scientific knowledge and quantitative methods available within management, sports management and the management of sporting competitions, it points to the possibility of more effective and efficient management of human, infrastructural, financial and IT resources, within the context of time constraints (Dugalic, 2005).

Systematic studies focusing on the organization of sports events and competitions have, in addition to foreign theorists (Aaron \& Stewart, 1992; Farmer, Mulrooney, \& Amon, 1996; Pitts \& Stotlar, 1996), 
been dealt with in our region by many authors: Ljubojević (2001), Pelević (2011), Raič and Maksimović (2000), etc. This enabled a solid theoretical foundation for the management of sporting events, with each idea finding its application within modern sporting practice. On the other hand, it is also rooted in the idea that the constraints, factors and courses of action within the framework of these phenomena, are accurately identified through empirical research in sport, utilizing network planning techniques and other quantitative methods (Bloem \& Vermei, 2005; Vasiljević, 2013) The aim is therefore to offer an analysis through the confirmation of underlying assumptions and knowledge of management processes and techniques for organizing events, as well as eventually arrive at a conclusion that is able to interpret results in a way correspondent to effective sporting practices within the decision-making processes apparent in organizing sporting events, other special events such as jubilees, fairs, exhibitions, celebrations, press conferences (Van Der Wagen \& Carlos, 2009), or used for further research and application in the field of project management within sport.

\section{METHODS}

On the basis of the existing theoretical knowledge within the field of network planning and the CPM method, constructed and exhibited within the study is a hypothetical model designed by the author on the basis of previous research and their experience within the specialist field of sporting project management. The primary aim is to arrive at an understanding which will, through the assistance of this methodology, enrich sporting practice, as well as affirm the methods of network planning within the management of sport.

The organization of sporting events is, within sporting practice, realized through stages of project preparation, implementation, analysis and an evaluation of the actual sporting and financial results (HBS Press, 2006). In the preparation phase (conceptualization) the inputs (technical and financial support: capital sources), time, human resources, and the structure of revenue and expenses are analyzed, and risks (default event, ie cancellations, punching time, budget, etc.) projected. Concurrently, appropriate targets are set for the date, duration of activities, special deadlines and critical dates. The planning and organization of events includes:

- strategy formulation,

- the feasibility of the study and decision made,

- establishing objectives
- appointing an organizing committee and a coordinator of the committee (single) for various areas (security, security staff, measuring and testing, logistics and etc.)

- budgeting (financial plan),

- organizational structure,

- personnel by sector (volunteers, etc.),

- detailed planning,

- presentation of events including preparation, closing and cleaning, and

- evaluation, feedback and modification of future events (Dugalić, 2007).

The maintenance of sporting events is, as we can see, very complex, and it is thus desirable to accentuate in a systematic way, and using specific methodologies, activities that are crucial for the success of events. The expected outcome is in line with the set objectives, so that through the application of quantitative methods of network planning (CPM, PERT) through computer technology, these stages and activities translate into management models that can help sport officials plan events, organize activities and implement coordination during later phases, on a routine basis. In order to popularize, simplify and converge these techniques for use in sport, the paper presents a hand-drawn (manual) display of a CPM model.

This technique of network planning replaced the Gantt chart, as it provides: a comprehensive overview of the entire structure of planning, unambiguously shows the logical representations and interdependence of parts, informs of a critical situation in a timely manner and those parts of greatest burden, factors that adversely affect the completion date of the project, disturbing factors that threaten the progress and completion of the project, objectively comparing individual variants of the plan, so as to obtain a superior solution, relieving planners of their routine work especially within overly complex projects, carried out by computers, etc. (Roel, 2011; Weiss \& Gershon, 1989).

\section{RESULTS}

Forming project management models in sport is achieved in the following phases:

- the setting of model structures or the specification of activities necessary for the organization of events,

- defining the parameters of models which are predefined through a subjective assessment or estimation of parameters based on data derived 
from the past through experiences encountered during the organization of similar events (ie learning from practice),

- evaluation models relative to theoretical and empirical data, statistical criteria and tests, as well as the practical possibility of using the model for project management within the field of sporting events.

Activities of planning within project management in sport reflect:

- clearly defined stages within all processes, requiring time and resources (human, infrastructure, money, information in the form of equipment and accessories),

- waiting, or the process of project management that requires only the time consumed, and

- dependence, which does not waste any time or resources, and may be apparent or fictitious.

The basic functions of project management within sport are: planning project tasks, appointing the project team, organizing activities, managing the deadlines of project activities, controlling flow and resources, management during the project, and evaluating the project. Network planning, which is the recommended model for the management of sport, can be thoroughly and accurately analyzed and experiments conducted upon, so as to explain which results lead to concrete ideas for implementing projects. This means that managing the process of implementation is adaptable (can be monitored, controlled, corrected and adapted to the situation), which is highly applicable for sporting events which sometimes last only one day.

Tables 1 and 2, and Figures 1 and 2, as interpreted in the next chapter, present the results of the analysis which contribute to the rationalization of time resources, and with it, the causal scheduling of human, informational and monetary resources, according to the other authors (Đuričin \& Lončar, 2012).

\section{DISCUSSION}

Project management within sport has not, through the application of network planning techniques, found a wide application within sporting practice. There are many problems, difficulties and considerations that limit the use of these models within sport, primarily, the absence of a software package. In these circumstances, CASE tools or programs, such as Project Manager can be used. Training sport managers to manage projects within sporting practice through accredited courses can encourage their wider applica- tion. Citing it as a reason for not accepting the adequacy of the models within practice, some theorists state that they oversimplify reality, that situations within sporting practices change quicker than the models allow, that the data within sport marketing is often weak and inconsistent, and the models have therefore not shown a superiority in decision-making.

In order for the project management model to be more represented in sport, sports organizations need to equip themselves with proper management techniques, and correctly chose a model according to the desired area of activity (Chadwick, 2010). Shown below is a simplified example of a model from sporting practice, applied to the phase prior to a sporting event.

\section{Procedures for the implementation of projects}

The implementation of projects within sport using the CPM model has two supporting procedures, such as structure analysis and timing analysis. Activities should begin by analyzing the structure, which consists of: issuing a list of activities and the total time of preparation, and the construction of a network diagram for the sporting event, respectively those parts and controls relative to the rules of the construction. Questions for getting the Gantt model for event management are:

- Which actions must be completed immediately before?

- Which actions must begin immediately after?

- Which actions can be performed independently and in parallel?

- Can the observed activity are further divided into sub-activities?

Data lists of activities necessary for the holding of events are collected systematically, and some discovered during the construction of a network diagram. The rules for constructing a network diagram requires that every activity have its beginning and end expressed throughout the event (must start and finish within the event), as follows:

- The succeeding activity occurs only after the completion of the prior activity.

- Activities that take place simultaneously can occur only after the completion of the previous activity.

- When a subsequent activity begins during the activity preceding it, it is divided into sub-activities of the prior events.

- In the event of an activity which has the same beginning and end, a fictitious or mock activity is introduced with duration of zero. 
- Mock activities are used in other scenarios when requirements are incorporated if an event ends and begins with a number of activities that are interdependent.

- Within a series of activities, any number of apparent activities can be included, so long as they do not disrupt the structure of the network diagram, which is highly important when dismantling large diagrams into sub-networks of lesser scale.

- Each activity within the diagram can only be undone once, so in as much as the process of construction reveals the existence of either the loop, double line or closed cycle, they must, in the analysis of discrepancies, be removed.

Now, on the basis of prior and future activities, and initial and final events, all project events are numbered in ascending order, numbering initial (i) and final (j) events, where $i<j$. If this requirement is not fulfilled, the following problems arise:

- difficulties in identifying specific activities and frequent errors in writing the order of numbers,

\section{TABLE 1}

List of activities within the sports project for the flowchart.
- the application of computational methods to analyze network diagrams is made more difficult as the possibility of introducing some order to sequential data processing is made more difficult,

- processing on a computer requires increasing numbering network diagrams, and

- it is difficult to detect a closed cycle (loop) which needs to be removed from the network diagram.

For projects with a large number of activities, these problems are difficult to remove, and so adherence to these rules is very important. To create labels, symbols are used: $i, j=$ events or nodes, (i, j) activities in sequential order, $t_{i j}=$ duration of activity in units of time. In the planning and implementation of sporting events, all activities are grouped into tasks through the process of departmentalization, particularly commissions, committees or sectors (for safety, the hospitalization of participants, ceremonial part, logistics, surveillance, sports events, cooperation with the media, medical support, monitorial services...). In this way, the schedule of activities according to the type of job, is displayed within a single timeline, as shown in Table 1.

Defining the mission, goals, and name of the event, market research on similar, previously held events, data collection on the structure of the program, becoming familiar with legislation (laws, regulations

1. of sports associations), activities preceding the opening ceremony, information on potential participants, evaluation of attendance, a list of potential sponsors, fundraising plan. Elaboration of the concept.

Conduction of a feasibility study and, if requested, submission to the relevant bodies, including all

2 necessary information (name of the event, organizer, place and date, the goals of the organization,

activities, expectations regarding sport results and number of participants, program competition, approximate funds required for the project ).

Enactment of decisions regarding the organization and start of the sporting event, the candidates, if necessary,

3. submission and elaboration of the action plan of the sporting event, that is complete, necessary

. documents, notification of the relevant sporting bodies and commissions, obtainment of necessary approvals.

Evaluation of attendance: number of participants and visitors, determining the price of the registrati-

4. on fee, the number of participating sponsors and their approximate combined value, determining

the range of ticket prices, the expected response of the audience and its total value, number, value and schedule of concessions.

Organizing the structure of management: the appointing of a body or committee for coordination (or-

5. ganizational team), determining the level of coordination and the number of working bodies and commissions.

6. Appointment of remaining participants in the organizational structure, managers and executives, a plan of the number of volunteers and monitorial service.

7. Production cost estimate for all categories: place of origin, deadlines and implementers.

8. Revenue forecast and budget planning, in alignment with the cost estimate.

9 Creating licensing programs and media contacts to divide costs, and sell broadcasting rights.

10 Planning of sporting events: leadership plans, management and control activities during sporting events for all sequences required by the law, regulations and good management practices. 
Enactment of the financial plan (income and expense plan) through direct and indirect income and expenses, by categories, tariffs, price lists and bonuses for the various categories of actors, athletes,

11. audiences, sponsorship pool, media, stall owners... Strategies of differentiation with respect to the scope , time and method of payment.

Procurement plan: equipment, apparatus, equipment room, sound system, power supply, informatio-

12. nal materials, office supplies, hygiene products, medical supplies, ordering of food and drinks for refreshments and cocktails, promotional material, conceptual design plans and implementation of plaques, medals and certificates etc.

13. A plan to inform participants and the public, as well as paths and placement of information.

5

14. Study of public attitudes, equipping of facilities with necessary equipment and props at the chosen location, a logistics plan, planning accommodation and transfers if needed.

Plan of contact and manner of communication with all registered participants and interested parties (mem-

15. bers of the police, sponsors, the media, suppliers, the public, accreditation of participants and journalists).

16. Planned indicators: assessment of the efficacy of the event.

Appointment of working bodies and commissions, production of a calendar of activities and detailed ti-

17. meline for each sequence of activities, flowchart of competitive activities, development of a daily plan for the monitoring of and methods of evaluation for the implemented activities.

Execution plan by activity type, number, plan, number and distribution of volunteers by committees,

18. plan concerning the distribution of resources necessary for the implementation of activities, aligned with the cost estimate.

Marketing plan, promotions plan, business advertising and other forms of promotion, plan to enco-

19. urage sales in coordination with sponsors and tenants, an activities plan for promoters of the event and the media, creating print, audio and audio-visual materials, and press releases.

20. The preparation and signing of contracts for all product types, equipment, requisites, supplies (supply) and previously required services, according to the expenses.

An action plan for sponsors involved with the project, media activity plan, preferably in the form of a

21. special network plan of promotional activities with a detailed description of elements within the promotional mix (advertising, sales, promotions, and public relations), length of activities by media, within the specified budget, content, the method and means of communication.

22. Graphic, art, visual (mascots, logo, posters, catalogs), audio, audio-visual solutions, content editing, prototyping and final versions of promotional materials.

23. Crosscheck of candidates working on the project, selection and appointment of executives, contracts, their training and involvement in the project.

Audit of all plans (during the course of the sporting activity, security, movement of visitors, athletes and VIP, medical plans and courses of action, all dynamics of control of athletes: weight measure-

24. ment, medical examinations, doping control). Evaluation of activities by the organizational team, decision-making on the manner of coordination during the events, establishing a system of compensation for the executives (nature of rewards and penalties for lateness, tardiness or comments on the work of individual executives, etc.).

25. Development of educational materials, certificates, ID cards, uniforms, decorations and submission of participants.

Printed promotional material, audio and audio-visual, magnetic and other media records submitted to

26. sponsors, media houses and publicists according to the media plan in order to broadcast, deliver and realize the potential of attendees from the public and publicity.

Engagement of personnel in accordance with the contract and other forms of engagement. Checking

27. the cleaning and maintenance action plan before, during and after the conclusion of the event. Engagement of reporters and managers in ceremonies.

Finalization of the project, a confirmed list of participants and media sponsors, supplied promotional material, hired staff, checking: implementation of the contract, supply of equipment, props and

28. expendable supplies, approval of authorized institutions (organization of the inside order, professional sports associations), sending of invitations to guests to attend the opening ceremony of the sporting event.

Seminar for volunteers, check: techniques, measuring equipment, sound systems, electric power supply, coordination with external perpetrators (law enforcement, medical staff, journalists, reporters, cameramen, delegates, judges, sponsors, volunteers). Inspection of the arena and a written record of it. Insight into the finished material, medals, plaques, awards, audio recordings of the anthem, the preparation of protocols for the ceremony, announcing: the opening of the event, the winners and the closing the event. 
Furnishing works scheduled for the ceremony with decor and other necessary resources (flowers, special effects, etc.). Rehearsal of the opening ceremony, the awarding of medals and closing. The organi-

30. zation of cocktails for all the evening before the event to provide sponsors the opportunity to submit their hospitality, encourage media writing in the presence of athletes and those potential visitors who are interested. A registered plan for participants and competition schedules. The opening ceremony proceeded by the official sport, entertaining, and commercial programs.

\section{Analysis of time [start and comple- tion) required for the implementation of activities and projects}

On the basis of the activities described in Table 1 , one can construct a flow chart of activities, in accordance with the time line (Figure 1).

When the analysis of the structure is complete, the author of the project approaches the analysis of time or the end of one or more activities, or the entire project. The initial event is a condition in which an activity can begin, and the final event - the state of its completion. The initial and final event of the project, which reflect their beginning and end, are special cases, whereby the initial event has no preceding, and the final event, succeeding activities.

The analysis of time (relative to structure) varies according to the chosen model of network planning. When converting it to a mathematical model, differences between this and the PERT model can be observed. Within the CPM model, a deterministic and within PERT, a stochastic model occurs, which introduces uncertainty into the assessment of time for each individual activity. Within our literature, a sporting project which utilizes the PERT model can be found (Dugalić 2007), through which the cost of managing sporting events and implementing changes (shortening or extension) and simultaneously resources (savings or exceeding of the budget) can be monitored. The duration of activities is, within both models, utilized to calculate additional values through the analysis time. The number of the given time determines the choice between a CPM and PERT model, for PERT respects the most probable times (like the difference between optimistic and pessimistic time). The analysis of time within the CPM model (which is shown in this paper) is comprised of: determining the duration of activities, the progressive and retrograde calculation of the time of implementing the project, and finding a critical path as well as time reserves.

The progressive calculation of time is based on the earliest completed event of the project. The following is calculated:

- The earliest start to any activity $\left(t^{0}\right)$ which is equivalent to the earliest time at which the event has been achieved, and
- The earliest completed activities (i-j) are recorded as toj, and equivalent to the earliest time in which the event is achieved, and is obtained by adding the duration of the activity, and then activity with time $t_{i}^{0}$.

When the earliest completed set of activities which have $n$ as their final event are set (the earliest completion of the project $\mathrm{t}_{\mathrm{n}}^{0}$ ), the calculation of the latest beginning and the latest ending of any activity $(i-j)$ is enabled, and these values are entered into the network diagram. This is a retrograde calculation of time, and proceeds from the final event of a project and moves towards the initial event. In doing so, there is value in ensuring that the earliest time in which the project's completed event occurs is the shortest possible time required for its implementation, and the earliest occurrence of the completed event, at the same time of and no later than the occurrence of the event.

The progressive and retrograde computation of time provides values which are utilized to calculate the critical path and time reserves. A critical path is a series of interconnected activities within a sports project which extend between the beginning of and completion of an event as found in network diagrams, and combined, have the longest duration of time. All events which lie on the critical path have equal values of time between the earliest and latest time of occurrence, with the value of reserves respectively being zero (0). These activities, situated on the critical path are, within a network diagram, underlined by double lines, and the completion of these activities are also dependent on the completion of the sporting event's plan.

By completing the table for the network diagram, all the relevant sizes are found. The following data is for calculating the earliest completion of certain activities towards progressive procedures (Dobrenić, 1987):

$$
\mathrm{t}_{\mathrm{j}}^{(0)}=\mathrm{t}_{\mathrm{i}}^{(0)}+\mathrm{t}_{\mathrm{ij}}
$$

If the event has multiple paths, the earliest start to any activity which has $j$ as the starting event, is calculated by:

$$
\mathrm{t}_{\mathrm{j}}^{0}=\max _{\mathrm{i}}\left\{\mathrm{t}_{\mathrm{i}}^{0}+\mathrm{t}_{\mathrm{ij}}\right\} ; \quad \mathrm{t}_{\mathrm{i}}^{0}=0
$$

When the project cannot be completed within the planned time, it is necessary to make corrections to 


\section{FIGURE 1}

Flowchart of activities within the sports project, sketches the network plan.

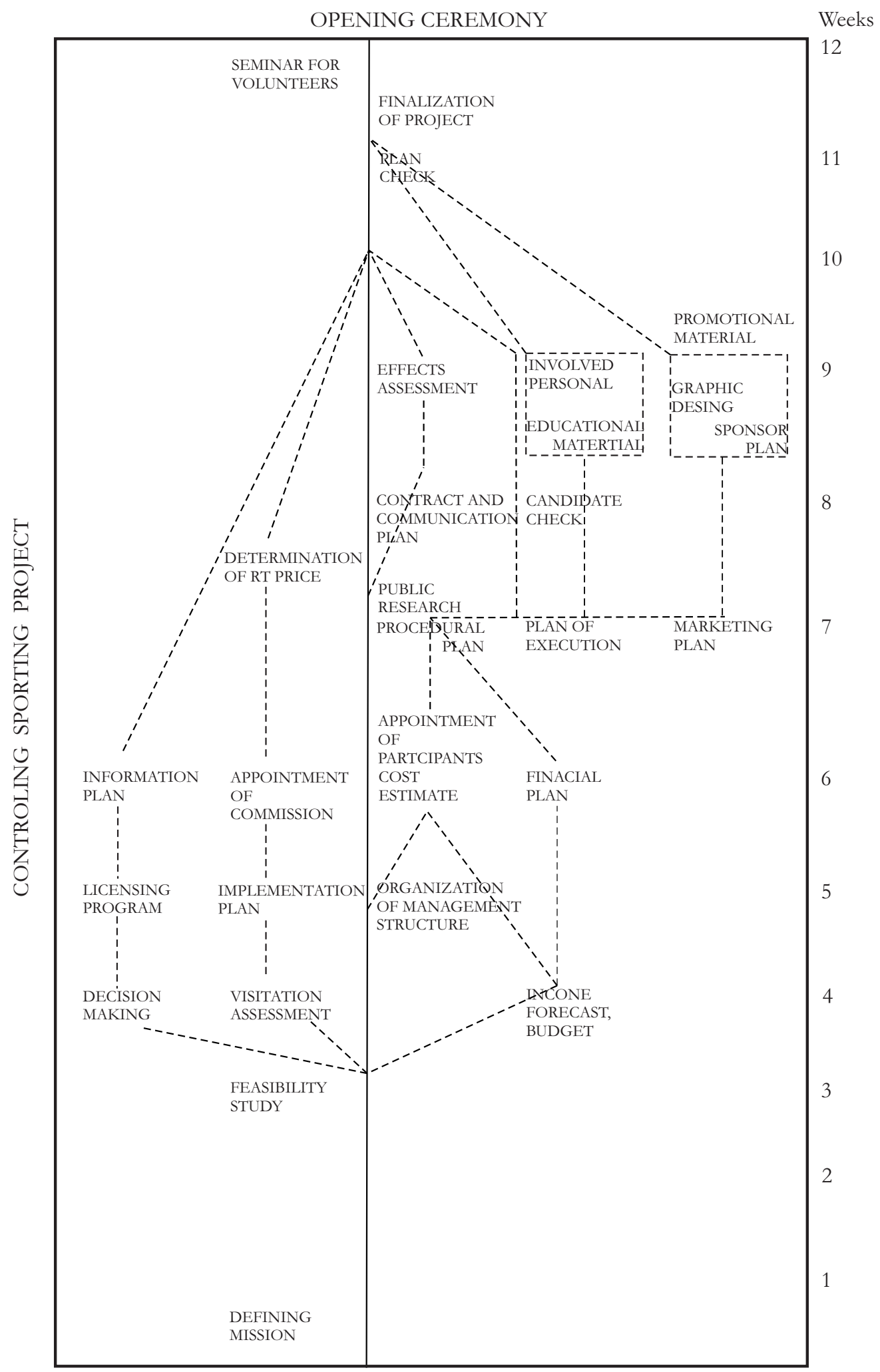

the network diagram by shortening the duration of activities through management processes, on the critical paths until the following is achieved:

$$
\mathrm{t}_{\mathrm{n}}^{0}=\mathrm{T}_{\mathrm{p}}=\mathrm{t}_{\mathrm{n}}{ }^{1}
$$

where $t_{n}{ }^{1}$ signifies the latest completion of the project.

The latest beginning of all activities $i-j$ is calcultaed by surtracting the duration of the activity from the latest completion of activities by:

$$
t_{i}^{1}=t_{j}^{1}-t_{i j}
$$


Where more activities arise from the initial event $\mathrm{i}$, the latest time taken to achieve that event is calculated by:

$$
\mathrm{t}_{\mathrm{i}}^{1}=\min _{\mathrm{j}}\left\{\mathrm{t}_{\mathrm{j}}^{1}+\mathrm{t}_{\mathrm{ij}}\right\} ; \quad \mathrm{t}_{\mathrm{n}}{ }^{1}=\mathrm{t}_{\mathrm{n}}{ }^{0}
$$

If for some activity (i-j) is $t_{i}{ }^{1}-t_{i}{ }^{0}-t_{i j}=0$, then this activity is referred to as a critical activity. For those activities in which the duration of activities is greater than the standard duration of the activity, i.e. greater than 0 , there emerges a reserve time.

$$
\begin{array}{rlrl}
\mathrm{t}_{1}{ }^{(0)}=0, \text { followed by: } \mathrm{t}_{2}{ }^{0} & \mathrm{t}_{5}{ }^{0}=30+10=40 \\
& =0+30=30 & & \mathrm{t}_{8}{ }^{0}=30+7=37 \\
\mathrm{t}_{4}{ }^{0}=30+3=33 & \mathrm{t}_{6}{ }^{0}=40+4=44 \\
\mathrm{t}_{3}{ }^{0}=30+5=35 & &
\end{array}
$$

\begin{tabular}{|c|c|c|c|c|c|c|c|c|c|}
\hline Events & \multirow{2}{*}{ Duration } & \multicolumn{2}{|c|}{ Earliest } & \multicolumn{2}{|c|}{ Latest } & \multicolumn{4}{|c|}{ Time reserves } \\
\hline Starting Closing & & Start & Finish & Start & Finish & Total & Available & Independent & \\
\hline 1 & 2 & 3 & 4 & 5 & 6 & 7 & 8 & 9 & \\
\hline \multirow{2}{*}{$i-j$} & & & & & & $(6-3-2)$ & $(4-3-2)$ & $(4-5-2)$ & \\
\hline & tij & $t_{i}^{0}$ & $t_{i}^{0}$ & $t_{i}^{1}$ & $t_{i}^{1}$ & $s_{i j}^{t}$ & $s_{i j}^{s}$ & $s^{n}{ }_{i j}$ & \\
\hline $1-2$ & 30 & 0 & 30 & 0 & 30 & 0 & 0 & 0 & $\mathrm{~K}$ \\
\hline $2-8$ & 7 & 30 & 37 & 30 & 48 & 11 & 0 & 0 & \\
\hline $2-3$ & 5 & 30 & 35 & 30 & 60 & 25 & 0 & 0 & \\
\hline $2-4$ & 3 & 30 & 33 & 30 & 68 & 35 & 0 & 0 & \\
\hline $2-5$ & $10^{\prime}$ & 30 & 40 & 30 & 40 & 0 & 0 & 0 & $\mathrm{~K}$ \\
\hline $5-6$ & 4 & 40 & 44 & 40 & 44 & 0 & 0 & 0 & K \\
\hline $5-7$ & 7 & 40 & 47 & 40 & 52 & 5 & $(-3), 0$ & $(-3), 0$ & \\
\hline $8-11$ & 5 & 37 & 48 & 48 & 53 & 11 & 6 & $(-5), 0$ & \\
\hline $3-9$ & 3 & 35 & 38 & 60 & 63 & 25 & 0 & $(-25), 0$ & \\
\hline $4-10$ & 3 & 33 & 36 & 68 & 71 & 35 & 0 & $(-35), 0$ & \\
\hline $7-11$ & 1 & 47 & 48 & 52 & 53 & 8 & 8 & $(-5), 0$ & \\
\hline $11-12$ & 2 & 48 & 50 & 53 & 60 & 10 & 0 & 1 & \\
\hline $9-13$ & 5 & 38 & 43 & 55 & 68 & 25 & 0 & $(-17), 0$ & \\
\hline $6-14$ & 15 & 44 & 59 & 44 & 59 & 0 & 0 & 0 & K \\
\hline $14-15$ & 7 & 59 & 66 & 59 & 74 & 8 & 0 & 0 & \\
\hline $16-24$ & 15 & 59 & 74 & 59 & 74 & 0 & 0 & 0 & K \\
\hline $17-24$ & 3 & 36 & 74 & 71 & 74 & 35 & 35 & 0 & \\
\hline $11-18$ & 2 & 48 & 50 & 53 & 67 & 17 & 0 & 1 & \\
\hline 11-19 & 5 & 48 & 53 & 53 & 58 & 5 & 0 & $(-5), 0$ & \\
\hline $13-20$ & 14 & 43 & 57 & 60 & 82 & 25 & 0 & $(-17), 0$ & \\
\hline $21-26$ & 5 & 53 & 63 & 63 & 68 & 10 & 5 & $(-5), 0$ & \\
\hline $22-26$ & 10 & 53 & 63 & 58 & 68 & 5 & 0 & $(-5), 0$ & \\
\hline $23-27$ & 10 & 50 & 60 & 67 & 77 & 17 & 0 & $(-17), 0$ & \\
\hline $12-24$ & 14 & 50 & 74 & 60 & 74 & 10 & 10 & 0 & \\
\hline $18-25$ & 7 & 50 & 57 & 67 & 77 & 20 & 0 & $(-17), 0$ & \\
\hline $26-28$ & 14 & 63 & 82 & 68 & 82 & 5 & 5 & 0 & \\
\hline $27-28$ & 5 & 60 & 82 & 77 & 82 & 17 & 17 & 0 & \\
\hline $24-28$ & 8 & 74 & 82 & 74 & 82 & 0 & 0 & 0 & K \\
\hline $28-29$ & 7 & 82 & 90 & 82 & 90 & 1 & 0 & 0 & \\
\hline $28-30$ & 8 & 82 & 90 & 82 & 90 & 0 & 0 & 0 & K \\
\hline
\end{tabular}

TABLE 2

Duration, time reserves and the calculation of critical times.

Legend: K - Critical path. 


$$
\begin{array}{lc}
\mathrm{t}_{7}{ }^{0}=40+7=47 & 66+0=66 \\
\mathrm{t}_{11}{ }^{0}=37+5=42=48 \max _{\mathrm{i}} & 59+15=74 \\
47+1=48 & \mathrm{t}_{25}{ }^{0}=50+7=57 \\
\mathrm{t}_{9}{ }^{0}=35+3=38 & \mathrm{t}_{26}{ }^{0}=\max _{\mathrm{i}} 53+5=58=63 \\
\mathrm{t}_{10}{ }^{0}=33+3=36 & 53+10=63 \\
\mathrm{t}_{12}{ }^{0}=48+2=50 & \mathrm{t}_{27}{ }^{0}=\max _{\mathrm{i}} 57+0=57=60 \\
\mathrm{t}_{13}{ }^{0}=38+5=43 & 50+10=60 \\
\mathrm{t}^{14}{ }_{0}=44+15=59 & 60+5=65 \\
\mathrm{t}_{15}{ }^{0}=\mathrm{max} 59+7=66 & \mathrm{t}_{28}{ }^{0}=\max _{\mathrm{i}} 63+14=77=82 \\
36+3=39 & 74+8=82 \\
57+0=57 & \mathrm{t}_{29}{ }^{0}=82+7=89 \\
\mathrm{t}_{16}{ }^{0}=59+0=59 & \mathrm{t}_{30}{ }^{0}=\max _{\mathrm{i}} 89+0=89=90 \\
\mathrm{t}_{17}{ }^{0}=36+0=36 & 82+8=90
\end{array}
$$

In such a case, the calculation of time reserves is undertaken so as to uncover those sub critical paths which have very low time reserves and can easily become critical. Non-critical activities contain a certain reserve time (total, free, independent) relative to the observed activity and those activities which immediately precede or follow on from the observed activities (Table 2).

Activities on the critical path are placed over events which have the same earliest and latest times: 1, 2, 5, $6,14,16,24,28$ and 30. Within the network diagram, the calculated values are entered into the left position of the corresponding events, and based on the assumption that the earliest completion time of the project is $\mathrm{t}_{\mathrm{n} 1}{ }^{0}=\mathrm{t}_{30}{ }^{0}=90$ days, and similarly, the latest completion time, i.e. $\mathrm{t}_{\mathrm{n}}{ }^{1}=\mathrm{t}_{30}{ }^{1}=90$ days. This is located within columns 3 and 4 of the Table 2 , in which additional formulas are utilized if the event $j$ has more activities.

$$
\begin{aligned}
& \mathrm{t}_{22}{ }^{1}=90-8=82 \\
& \mathrm{t}_{21}{ }^{1}=82-8=74 \\
& \mathrm{t}_{20}{ }^{1}=82-5=77 \\
& \mathrm{t}_{19}{ }^{1}=82-14=68 \\
& \mathrm{t}_{18}{ }^{1}=77-10=67 \\
& \mathrm{t}_{17}{ }^{1}=74-14=60 \\
& \mathrm{t}_{16}{ }^{1}=\min _{\mathrm{j}} 77-7=67 \\
& 67-0 \\
& \mathrm{t}_{15}{ }^{1}=68-10=58 \\
& \mathrm{t}_{14}{ }^{1}=68-15=63 \\
& \mathrm{t}_{13}{ }^{1}=60=74-10 \\
& \mathrm{t}_{12}{ }^{1}=74-3=71 \\
& \mathrm{t}_{11}{ }^{1}=74-15=59 \\
& \mathrm{t}_{9}{ }^{1}=59-15=44 \\
& \mathrm{t}_{8}{ }^{1}=60-5=55 \\
& \mathrm{t}_{7}{ }^{1}=\min _{\mathrm{j}} 60-2=58 \\
& 67-2=65=53 \\
& 58-5=53 \\
& \mathrm{t}_{6}{ }^{1}=53-1=52 \\
& \mathrm{t}_{5}{ }^{1}=71-3=68 \\
& \mathrm{t}_{4}{ }^{1}=55-3=52 \\
& \mathrm{t}_{3}{ }^{1}=53-5=48 \\
& \mathrm{t}_{2}{ }^{1}=\min _{\mathrm{j}} 44-4=40 \\
& 52-7=45 \\
& \mathrm{t}_{1}{ }^{1}=\min _{\mathrm{j}} 52-5=47 \\
& 68-3=65=30 \\
& \mathrm{t}_{10}{ }^{1}=\min _{\mathrm{j}} 74-7=67=59 \\
& 40-10=30 \\
& 59-0 \\
& 48-7=41 \\
& \mathrm{t}_{0}{ }^{1}=30-30=0
\end{aligned}
$$

Through the retrograde procedure, the latest start to certain activities can now be calculated by $\mathrm{t}_{\mathrm{i}}{ }^{1}=\mathrm{t}_{\mathrm{i}}{ }^{1}$ - $t_{i j},(6)$, and these values are entered in the 5 th and 6th columns of Table 2:

The calculation of time reserves is undertaken in order to uncover sub critical paths, which have very little time reserves and can easily become critical. The calculated time reserves which have a negative signification of time are exclusively applied to independent time reserves and have a value of 0 , as:

$$
\mathrm{s}_{\mathrm{ij}}{ }^{\mathrm{n}}=\max \left\{0, \mathrm{t}_{\mathrm{j}}^{0}-\mathrm{t}_{\mathrm{i}}^{0}-\mathrm{t}_{\mathrm{ij}}\right\}
$$

Activities which are not on the critical path contain the reserved time relative to those activities which immediately precede or follow behind the observed activity. There exist: total, free and independent reserves of time. Within the table, the value of time reserves is calculated by subtracting the value of individual columns.

The total reserve time (column 7 in Table 2), is given by:

$$
\mathrm{s}_{\mathrm{ij}}^{\mathrm{t}}=\mathrm{t}_{\mathrm{j}}^{1}-\mathrm{t}_{\mathrm{i}}^{0}-\mathrm{t}_{\mathrm{ij}}
$$

for each activity, e.g. 2-8 amounts to 11 days and represents the difference between the maximum time both allowed and made available to perform the activities, and the time of its duration. This means that the duration of these activities can be moved 11 days from the earliest start, so long as the project's completion date is not compromised. If this time reserve is loaded in full, the earliest and latest completion coincide, and from this position, a new critical path may emerge as the following activities' time reserves are likewise exhausted.

Free time reserves emerge in situations where in the event of j, two or more activities are entered, and which play an important role in shortening or reshaping the network diagram. This is calculated by:

$$
\mathrm{s}_{\mathrm{ij}}^{\mathrm{s}}=\mathrm{t}_{\mathrm{j}}^{0}-\mathrm{t}_{\mathrm{i}}^{0}-\mathrm{t}_{\mathrm{ij}}
$$

For activities 17-24, it amounts to 35 days, meaning that the duration of that activity may be extended or moved by this amount, whilst still maintaining the earliest starts for the following activities.

Independent reserve times exist within activities 11-12 and 11-18 for periods of 1 , meaning that the duration of these activities may be extended by this amount, the duration of which corresponds to moving the deadline of the earliest commencement of the activity. Within the network diagram, this shift will not affect the time relations of other activities if the shift is carried out within a day.

The probationary time reserve in not, in this example, calculated (it refers to the events of the network, 
FIGURE 2

The insertion of time values to events within the network diagram.

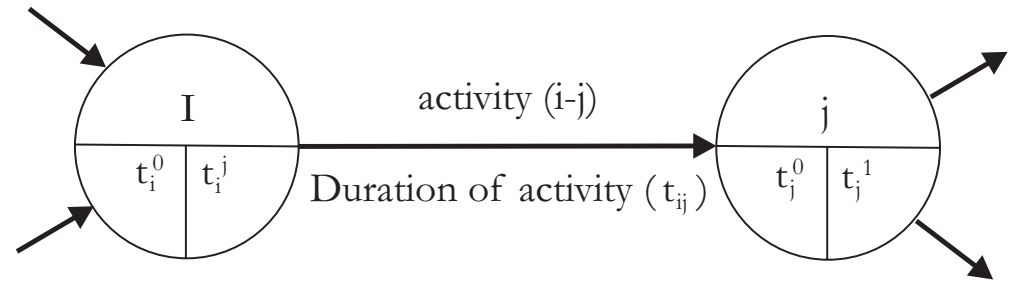

FIGURE 3

The network plan of the management of sporting projects.

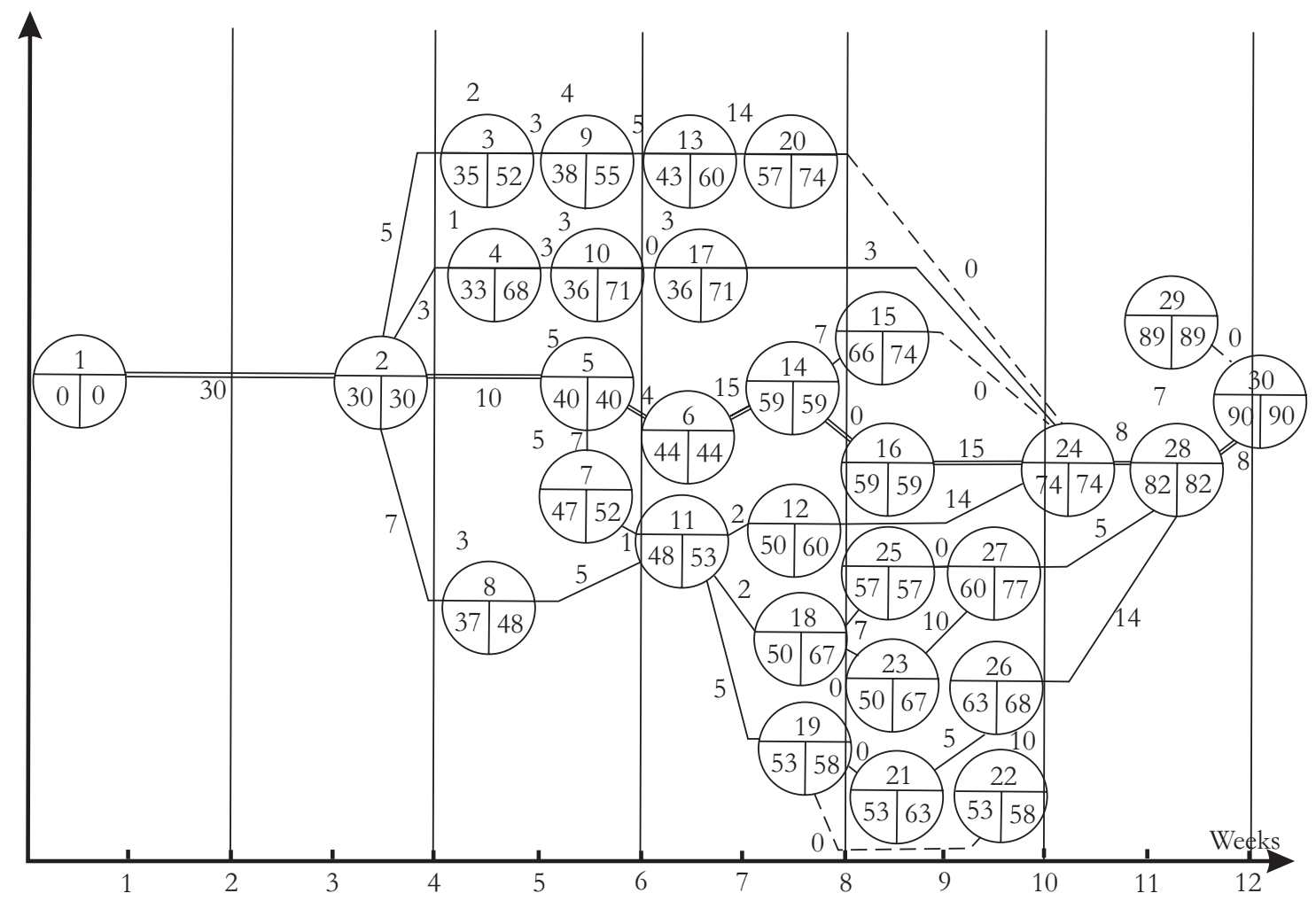

Legend: Solid line - Course of ordinary activities; Dotted line - Relationship between the activities that have zero or negative independent reserve; Double line - Trajectory of activities lying on the critical path.

as opposed to other time reserves which are related to activities). If carried out, the calculation is conducted through the formula:

$$
\mathrm{s}_{j}^{\mathrm{u}}=\mathrm{t}_{j}^{1}-\mathrm{t}_{1}^{0}
$$

It defines the criticality of events and serves as a measure of the sub criticality of events.

The position of time values within network diagrams are displayed as follows in Figure 2.

The appearance of the final network plan within sport project management is shown in Figure 3.

\section{CONCLUSION}

If implemented to sport, the network planning model could significantly contribute to the resolution of organizational problems specific to planning complex sporting and special events. When one intends to compete for the championship, it is imperative that they go through certain procedures with a number of requirements relative to the rules set by sporting associations, and the purpose of expense and management requirements, so that candidacy within sporting events may be realized in a manner through which the organizer is able to achieve positive economic and other effects.

This paper presents some quantitative theory (the models of network planning) by presenting a practical explanation of the models through a practice-based example which seeks to affirm their use in sport. The paper likewise aims to encourage and motivate the development of software through which the use of 
these models within sport is augmented, and therefore demands from management teams who organize these sporting projects, that its techniques and methods are promoted in accordance with the needs and anticipated levels of technological and informational developments.

\section{REFERENCES}

Aaron, S., \& Stewart B. (1992). Sports management. Melbourne, AU: Allen \& Unwin Pty Ltd. PMCid: PMC1737143

Appenzeller, H. L. (2000). Successful sport management. 2nd ed. Durham, NC: Carolina Academic Press.

Bloem, M., \& Vermei, A. (2005). The olympic road to performance improvement. Performance Improvement, 44(6), 7-13. doi: 10.1002/ pfi.4140440604

Chadwick, J. S. (2010). Sportski menadžment [The business of sport mangement]. Zagreb, HR: Mate.

Dobrenić, S. (1987). Operativno istraživanje [Operational research]. Varaždin, HR: Fakultet organizacije i informatike.

Dugalić, S. (1995). Lansiranje novog proizvodnog asortimana [The launch of the new product assortment]. Plasman i triziste, 2, 21-31.

Dugalić, S. (2005). Finansijski i marketinški aspekti strategija u sportu [Financial and marketing aspects of the strategy in sport]. Belgrade, RS: Viša škola za sportske trenere.

Dugalić, S. (2007). Menadřment sportskib objekata [Management of sports facilities]. Belgrade, RS: Visoka škola za sport.

Đuričin, D., \& Lončar, D. (2012). Menadžment pomoću projekata [Management by projects]. Belgrade, RS: Centar za izdavačku delatnost Ekonomskog fakulteta u Beogradu.

Farmer J. P., Mulrooney L. A., \& Amon R. Jr. (1996). Sport facility planning and management. Morgantown, WV: Fitness Information Technology, Inc.

Harvard Business School Press. (2006). Menadžment projekta [Project management]. Belgrade, RS:

Data status.

Received: April 19, 2013

Revision received: September 29, 2013

Accepted: October 17, 2013
Kelley, J. (1961). Critical path planning and scheduling: Mathematical basis. Operations Research, 9(3), 1091-1105. doi: 10.1287/ opre.9.3.296

Kelley, J., \& Morgan, W. (1959). Critical-Path Planning and Scheduling. Proceedings of Eastern Joint Computer Conference (pp. 160-173). Boston, MA, December 1959.

Ljubojević, Č. (2001). Menadð̌ment i marketing u sportu [Management and marketing in sport]. Belgrade, RS: ̌̌elnid,

Pelević B. (2011). Menadžment sportskih takmičenja [Management of sports events]. Belgrade, RS: Visoka sportska i zdravstvena škola.

Pitts B. G, \& Stotlar, D. (1996). Fundamentals of sport marketing. Morgantown, WV: Fitness Information Technology, Inc.

Raič, A. (2006). Sportski menadžment kao profesija i kao nauka [Sports management as a profession and as a science]. In Đ. Nićin (Ed.), 2nd International conference »Management in sport« (pp. 17-24). Belgrade, RS: Fakultet za menadžment u sportu Univerziteta »Braća Karić«.

Raič, A., \& Maksimović, N. (2000). Sportski menadžment [Sports management]. Novi Sad, RS: Fakultet fizičke kulture.

Roel, G. (2011). Project management. Groningen, NL: Noordhoff Uitgevers B.V

Van Der Wagen, L., \& Carlos, B. R. (2009). Upravljanje događanjima [Event management]. Beograd, RS: Mate d.o.o.

Vasiljević, D. (2013). Material requirements planning in manufacturing of sport industry equipment. In D. Životić and V. Šiljak (Eds.), Proceedings of 8th International conference »Management in sport» (pp. 324-330). Belgrade, RS: Fakultet za menadžment u sportu Alfa univerziteta.

Weiss, H. J., \& Gershon, M. E. (1989). Production and operations management. Boston, MA: Allyn and Bacon
Correspondence to:

Sretenka Dugalić, PhD

Visoka sportska i zdravstvena škola

Toše Jovanovića 11 11000 Belgarde Serbia

Phone: 00381112380537

E-mail: sretenkadugalic@yahoo.com 